\title{
Sociocultural Factors Related to Work Ethics among Nurses: A Quantitative Study in Ilam, Iran
}

\author{
Jahangir Jahangiri, ${ }^{1,}$ Mohammad Hassan Heidarian, ${ }^{1}$ Mahsa Nouri Koochi, ${ }^{1}$ and Mohammadreza \\ Shalbafan ${ }^{2}$ \\ ${ }^{1}$ Department of Sociology and Social Planning, Shiraz University, Shiraz, Iran \\ ${ }^{2}$ Mental Health Research Center, Iran University of Medical Sciences, Tehran, Iran \\ "Corresponding author: Jahangir Jahangiri, Eram Place, Shiraz University, Shiraz, Fars, Iran. Tel: +98-9171184112, E-mail: jjahangiri@gmail.com
}

Received 2017 February 15; Revised 2017 April 15; Accepted 2017 June 10.

\begin{abstract}
Background: Nurses constantly deal with ethical concerns, as their decisions may cause irreversible consequences for the patients. This study aimed to investigate work ethics among nurses, based on Weber's theory of work ethics.

Methods: In this quantitative cross sectional survey, data were collected using the multidimensional work ethics profile. Cronbach's alpha and face validity were applied for measuring the reliability and validity of the questionnaire, respectively (total Cronbach's alpha, 0.82). Considering the total sample size of the study (n, 283), including all active nurses of public hospitals across Ilam, Iran, no sampling method was applied and data were collected through whole counting.

Results: A direct significant correlation was observed between work ethics and religious identity $(\mathrm{P}=0.000)$, as well as work ethics and use of media $(\mathrm{P}=0.01)$. In addition, there was a significant gender difference in work ethics, as female nurses showed higher work ethics $(\mathrm{P}=0.038)$. However, there was no significant difference among nurses with different educational levels in terms of work ethics; similar findings were reported for other variables, such as income, work experience, and marital status. Based on the regression analysis, religious identity, use of media, and social class could explain $15.9 \%$ of variance in the dependent variable (work ethics).

Conclusions: Religion plays an important role in work ethics among nurses. In addition, media encouragement to work and create wealth may motivate nurses to work harder and enhance their work ethics. Nurses from higher social classes generally decentralize work in their lives and consequently have poorer work ethics. In addition, it seems that gender discrimination against men in nursing has a negative impact on their work ethics.
\end{abstract}

Keywords: Ethic, Work Ethic, Nurse, Public Hospitals

\section{Background}

Nurses are recognized as the frontline health workers in hospitals. As key members of every hospital, they play an important role in the quality of hospital services and affect patients' health from different aspects. In many cases, nurses' performance can lead to the survival or death of patients (1). In every organization, members' behaviors can be classified as positive and negative. Certainly, an organization requires its members to show positive behaviors and perform their tasks accurately. However, if the organization fails to meet the employees' requirements and needs, positive behaviors may gradually become negative and unconstructive (2).

Due to the specific nature of nursing profession, unfavorable work conditions in hospitals can exert severe ethical pressure on the staff and cause disappointment, internal conflicts, dissatisfaction, psychological and physical disorders, and even quitting among nurses (3). According to global studies, evaluation of nurses' work conditions in- dicates the shortage of nursing staff and human resources $(4,5)$.

Since nursing decisions have direct impacts on people's lives and may be associated with irreversible consequences, nurses are always dealing with ethical concerns. In fact, ethics is a necessary element of nursing profession (6), and understanding the nurses' performance depends on the understanding of ethical issues. Different studies have shown that organizational, social, cultural, economic, educational, medical, familial, and individual factors and resources can affect the way nurses deal with ethical challenges and generally their performance in hospitals (3, 6-9).

With this background in mind, the present study aimed to investigate work ethics and the associated factors among nurses. Therefore, the main study question is concerned with sociocultural factors associated with work ethics among nurses. Overall, work ethics indicates one's commitment to values and importance of work (10). The 
present research is based on Max Weber's theory related to work ethics, as explained in the "protestant ethic and the spirit of capitalism" (11). Although Weber is known as the founder of interpretive sociology, he has also tried to discover the casual relationships and patterns in society, as argued by Seidman (12). In the present study, the data collection tool was a questionnaire, which has been derived from extensive studies by Miller and colleagues (10), using Weber's theory as the theoretical framework; in other words, this questionnaire is based on Weber's theory.

Weber states that the foundation of ethics is hard work and shunning of leisure for “...earning more and more money, combined with the strict avoidance of all spontaneous enjoyment of life" and avoidance of "ostentation and unnecessary expenditure" as the accepted way of life. This prudent approach towards making and spending money led to a sense of independence and self-reliance, which aided the rise of capitalism. Weber then stresses the centrality of work in people's lives, as demonstrated by his view that "They were men who had grown up in the hard school of life...shrewd and completely devoted to their business". Not surprisingly, a prominent component of work ethics is constructive use of time. Specifically, Weber states, "Waste of time is thus the first and in principle the deadliest of sins".

Finally, Weber addresses the high moral fiber that individuals with ethical standards demonstrated in their daily affairs: “...Only by virtue of very definite and highly developed ethical qualities that it has been possible for him to command the absolutely indispensable confidence of his customers and workmen". An individual subscribing to these beliefs also "... avoids ostentation and unnecessary expenditure, as well as conscious enjoyment of his power". Therefore, consistent with Weber's early theory, work ethics seems to be a multidimensional set of values $(10,11)$.

\section{Methods}

This cross sectional study with a quantitative approach was performed between July 23, 2015 and January 21, 2016 in Ilam, the capital of Ilam Province, Iran at 3 public hospitals of Ilam. According to our inquiry from Ilam University of Medical Sciences at baseline, there were 283 active nurses in these public hospitals.

\subsection{Sampling}

This study was conducted on 283 active nurses in public hospitals of Ilam. Considering the total size of the statistical population, no sampling method was applied, and data collection was performed through whole counting. Finally, $70.3 \%$ of the total target population participated in the study (199 out of 238). Three major reasons prevented researchers' access to the entire target population:1) nonparticipation of all nurses for reasons such as personal issues and high workload; 2) absence of some nurses from hospital wards due to reasons such as working in administrative sectors and leave of absence; and 3) refusal of head nurses in some wards (due to the serious conditions of patients or other special circumstances) to allow researchers in the respective wards, despite prearrangements and permissions.

\subsection{Data Collection}

To measure work ethics, the multidimensional work ethics profile (MWEP) was used. In fact, the present research is to some extent based on a research study by Miller and colleagues (2002) entitled, "The meaning and measurement of work ethics: construction and initial validation of a multidimensional inventory". The aim of their study was to present a comprehensive conceptual definition of work ethics and to construct and evaluate an inventory to examine work ethics. Miller et al. had considered all the presented scales related to work ethics, including the protestant ethic scale, pro-protestant ethic scale, protestant work ethic scale, spirit of capitalism scale, work and leisure ethic scale, and eclectic protestant ethic scale.

MWEP is a 65-item inventory, which measures 7 conceptually and empirically distinct facets of work ethic construct. This highly valid and reliable inventory has been employed in different studies across the world (10, 13-15). To achieve the desired validity and reliability for the Farsi version of MWEP and to adjust it with Iran's cultural context, different measures were taken. First, after translating the inventory from English to Farsi, it was retranslated into English. Then, the validity of the translated version was assessed by 4 experienced translators, and the required modifications were made.

After confirming the Farsi version of MWEP, it was presented to 7 experts in the fields of sociology, management, medical sciences, and nursing to achieve the desired face validity. The final questionnaire was applied to 30 subjects as pretest, and the results were analyzed in SPSS version 21 (Chicago, IL, USA). At this stage, internal consistency of the items was measured using Cronbach's alpha, and the required modifications were made. Finally, MWEP, along with questions concerned with work ethic-related factors, was used as the final questionnaire. This self-report questionnaire was distributed among the subjects and completed.

\subsection{Research Variables}

In this study, work ethics was measured as the dependent variable with 7 dimensions: self-reliance, moral- 
ity/ethics, leisure, hard work, centrality of work, wasted time, and delay of gratification. The independent variables included demographic, educational, social, cultural, economic, and religious variables. To measure religious identity, we used a Likert scale with 6 items, and to analyze use of media, we applied a 6-item Likert scale.

\subsection{Data Analysis}

Data analysis was performed in SPSS version 21 (Chicago, IL, USA). In each stage of bivariate analysis, Pearson's correlation coefficient test, t test, and F-test were used to investigate the relationship of each independent variable with the dependent variable. In addition, to perform multivariate analysis and investigate the collective effect of all independent variables on the dependent variable, stepwise multivariate regression analysis was applied. In this method, different variables were included in the order of importance to explain the dependent variable. Finally, variables with no explainable role were excluded.

\section{Results}

\subsection{Descriptive Findings}

According to the descriptive findings, the mean age of the study population was 32.14 years (maximum, 52 years; minimum, 23 years). In total, $56.3 \%$ of the subjects were women and $43.7 \%$ were men. In addition, $62.1 \%$ of the respondents were married and $37.9 \%$ were single. The majority of nurses (87.4\%) had a Bachelor's degree and the rest (12.6\%) had a Master's degree or PhD. The majority of the study population (91.4\%) were Kurd, followed by Lurs (5.7\%), and Fars (2.9\%).

\subsection{Bivariate Analysis Results}

Table 1 shows the results of Pearson's correlation test between the independent and dependent (work ethics) variables. The results suggested a significant relationship between religious identity and work ethics among nurses at a significance level of $99 \%(r, 0.363 ; P=0.000)$. In addition, the findings suggested a significant relationship between use of media and work ethics among nurses at a significance level of 95\% ( $r, 0.199 ; \mathrm{P}=0.010)$. Therefore, work ethics of nurses promotes by improving religious identity and use of media.

Table 2 presents the t test results for work ethics with respect to the respondents' gender. The t test results ( $T$, -2.089; $\mathrm{P}=0.038$ ) showed a significant gender difference in terms of work ethics at a significance level of $95 \%$. The mean score of work ethics was higher in female nurses
(233.24) in comparison with males (225.17), indicating the higher level of work ethics among the former group.

Table 3 presents the F-test results for work ethics based on the subjects' social class. The F-test results showed no significant difference among nurses from different social classes in terms of work ethics ( $F, 1.890 ; \mathrm{P}=0.133)$.

The F-test results for work ethics showed no significant difference in terms of social class, work experience, education, and income $(\mathrm{F}, 1.890, \mathrm{P}=0.133 ; \mathrm{F}, 1.53, \mathrm{P}=0.19 ; \mathrm{F}, 1.46, \mathrm{P}=$ $0.22 ; \mathrm{F}, 0.55, \mathrm{P}=0.69$, respectively). In addition, the t test results showed no significant difference in work ethics with respect to marital status $(\mathrm{T},-1.44 ; \mathrm{P}=0.15)$.

\subsection{Multivariate Analysis Results}

In this study, stepwise multivariate regression was applied. In this method, different independent variables were included in the order of importance to explain and predict the dependent variable. The statistical results (Table 4) showed that the regression model included 3 stages at significance level; in each stage, a new variable was incorporated. The results suggested that religious identity $(\beta, 0.337 ; \mathrm{P}=0.000)$ had the greatest effect on work ethics, explaining $0.124 \%$ of the variance.

In addition, use of media $(\beta, 0.149 ; \mathrm{P}=0.040)$ and social class $(\beta,-0.148 ; \mathrm{P}=0.141)$ could explain $0.018 \%$ and $0.017 \%$ of variance in the dependent variable. There was a direct correlation between religious identity and use of media, whereas social class and work ethics were inversely correlated. In other words, work ethics promoted by improving religious identity and increased media use. On the other hand, work ethics deteriorated with increasing social class. In total, these 3 variables could explain $15.9 \%$ of internal variance in the dependent variable $\left(\mathrm{R}^{2}, 0.159\right)$.

\section{Discussion and Conclusion}

After the ideas of modern work ethics and protestant work ethics were put forward by Weber, researchers all around the world started to investigate the correlation of different religions with work ethics $(11,16)$. In addition, several studies have been recently performed on Islamic work ethics in different countries (17-19).

Sayadi et al. (17) Murtaza et al. (16), and Sehhat et al. (20) showed a significant positive correlation between Islamic work ethics and performance of employees in different organizations and professions. According to Tabrizi et al. (21) internalized religious beliefs creates legal and lawful commitments such as paying more attention to the law and respecting the rights of others. Also Kalateh Sadati et al. (22) showed that the monotheistic religions have a massive capacity to help health institutions. Religion and 
Table 1. Pearson's Correlation Test Between Work Ethics and Independent Interval Variables

\begin{tabular}{lcccc}
\hline Independent Variable & Dependent Variable & Mean & Standard Deviation & Correlation Coefficient \\
\hline Religious identity $^{\mathrm{a}}$ & Work ethics & 21.120 & 4.709 & 0.363 \\
Use of media & Work ethics & 11.546 & 2.852 & 0.000 \\
\hline
\end{tabular}

${ }^{a}$ All the respondents identified themselves as Muslims.

Table 2. The T Test Results for Work Ethics in Terms of Gender

\begin{tabular}{lcccccc}
\hline Dependent Variable & Gender & Frequency & Mean & Standard Deviation & TValue & Significance Level \\
\hline \multirow{2}{*}{ Work ethics } & Male & 80 & 225.17 & 26.75 & -2.089 \\
& Female & 105 & 233.24 & 23.19 & 0.038 \\
\hline & & & & & \\
\hline
\end{tabular}

Table 3. The F-Test Results for Work Ethics Based on Social Class

\begin{tabular}{|c|c|c|c|c|c|c|}
\hline Dependent Variable & Class & Frequency & Mean & Standard Deviation & F Value & Significance Level \\
\hline \multirow{4}{*}{ Work ethics } & High & 4 & 231.33 & 11.59 & \multirow{4}{*}{1.890} & \multirow{4}{*}{0.133} \\
\hline & Moderate to high & 122 & 231.91 & 25.12 & & \\
\hline & Moderate to low & 52 & 223.06 & 23.27 & & \\
\hline & Low & 7 & 223.50 & 35.11 & & \\
\hline
\end{tabular}

Table 4. Dependent Variables of the Model as Work Ethics Predictors

\begin{tabular}{|c|c|c|c|c|c|c|c|}
\hline Stages & Variables & Coefficients of Determination $\left(\mathbf{R}^{2}\right)$ & Corrected Coefficient of Determination $\left(\mathbf{R}^{2}\right)$ & B & $\beta$ & t Test & Sig. T \\
\hline First & Religious identity & 0.129 & 0.124 & 1.760 & 0.337 & 4.676 & 0.000 \\
\hline Second & Use of media & 0.152 & 0.142 & 1.330 & 0.149 & 2.066 & 0.040 \\
\hline Third & Social class & 0.174 & 0.159 & -6.394 & -0.148 & -2.063 & 0.041 \\
\hline
\end{tabular}

its context play an important role in the health domain; policy makers and governmental institutions on the one hand and treatment teams, especially doctors and nurses one the other, should pay it due attention in order to empower patients. These findings are consistent with the results of the current study, showing that nurses' religious identity contributes to the improvement of work ethics. Since all participants were Muslims, it can be concluded that Islamic principles improve the work ethics and performance of hospital nurses.

As earlier noted, scholars have started investigations on the concept of work ethics in different societies and have found religion to be the major source of work ethics. For instance, studies have examined work ethics in societies with different dominant religions such as Confucianism, Buddhism, Hinduism, and Judaism (23). Therefore, questioning the common properties or principles of work ethics in different religions may be a good subject for future investigations.
According to global studies, women comprise the dominant nursing population, and there is a strong gender discrimination against men $(24,25)$. Clow et al. (26) and Takase et al. (27) showed that the incongruity between social and professional roles affects people's work ethics. Moreover, stereotypical thoughts about the feminine nature of nursing impose great pressure on male nurses. The results of the present study suggested women's higher work ethics. Therefore, it seems that stereotypical thoughts and sexism play a significant role in this area. Since there is no inconsistency between the public and nurses' perceptions of nursing profession, work conditions are simpler for women than men.

Today, mass media plays a significant role in people's sociability. In this regard, Herring (28) showed that TV programs affect people's work ethics. The results of the current study suggested a significant correlation between media exposure and work ethics. It seems that since the majority of media outlets display a negative image of the 
unemployed and encourage people to work and create wealth, greater media exposure can produce a better sense of self among hospital nurses and motivate them to work harder.

The results of the present study suggested an inverse correlation between social class and work ethics among nurses. In other words, work ethics deteriorates with increasing social class. In fact, nurses from higher social classes typically do not believe in hard work, and working is not a central part of their life. Therefore, they do not work as hard as other nurses, and as a result, they obtain lower scores on work ethics indices.

The present study had some limitations. First, it is not possible to generalize the findings to other populations, except the target population. Therefore, it is recommended to perform further research in different cities and discuss the similarities and differences to reach more precise conclusions about the findings. In addition, considering the cross sectional design of the study, we could not collect data over time to learn more about the possible contributing factors.

On the other hand, the main strength of this study is the researchers' attention to work ethics, a subject which has not been discussed or studied vastly, especially in Iran; in fact, the majority of studies are restricted to professional ethics. The second strength is the use of MWEP questionnaire, which had not been used in Iran before. Use of this questionnaire can help compare the present results with other foreign studies using the same scale for the analysis of work ethics.

\subsection{Ethical Considerations}

Ethical issues (including plagiarism, informed consent, misconduct, data fabrication and/or falsification, double publication and/or submission, and redundancy) were completely observed by the authors.

\section{Acknowledgments}

We would like to thank the research deputy of Ilam University of Medical Sciences for granting permission for data collection in public hospitals of Ilam. We also express our gratitude to all the nurses working in these hospitals. The authors declare no conflicts of interest.

\section{References}

1. Needleman J, Hassmiller S. The role of nurses in improving hospital quality and efficiency: real-world results. Health Aff (Millwood). 2009;28(4):w625-33. doi: 10.1377/hlthaff.28.4.w625. [PubMed: 19525289].

2. Abdullah A, Halim FW. The influence of work ethic and counterproductive work behaviour of civil servants. J Technol Manage Bus. 2016;3(1):1-14.
3. Ulrich C, O'Donnell P, Taylor C, Farrar A, Danis M, Grady C. Ethical climate, ethics stress, and the job satisfaction of nurses and social workers in the United States. Soc Sci Med. 2007;65(8):1708-19. doi: 10.1016/j.socscimed.2007.05.050. [PubMed: 17619068].

4. Coomber B, Barriball KL. Impact of job satisfaction components on intent to leave and turnover for hospital-based nurses: a review of the research literature. Int J Nurs Stud. 2007;44(2):297-314. doi: 10.1016/j.ijnurstu.2006.02.004. [PubMed:16631760].

5. Aiken LH, Cheung RB, Olds DM. Education policy initiatives to address the nurse shortage in the United States. Health Aff (Millwood). 2009;28(4):w646-56. doi: 10.1377/hlthaff.28.4.w646. [PubMed: 19525285].

6. Dehghani A, Mosalanejad L, Dehghan-Nayeri N. Factors affecting professional ethics in nursing practice in Iran: a qualitative study. BMC Med Ethics. 2015;16:61. doi: 10.1186/s12910-015-0048-2. [PubMed: 26354119].

7. Corley MC. Nurse moral distress: a proposed theory and research agenda. Nurs Ethics. 2002;9(6):636-50. doi: 10.1191/0969733002ne557oa. [PubMed:12450000].

8. Zuzelo PR. Exploring the moral distress of registered nurses. Nurs Ethics. 2007;14(3):344-59. doi: 10.1177/0969733007075870. [PubMed: 17459818].

9. Grady C, Danis M, Soeken KL, O'Donnell P, Taylor C, Farrar A, et al. Does ethics education influence the moral action of practicing nurses and social workers? Am J Bioeth. 2008;8(4):4-11. doi: 10.1080/15265160802166017. [PubMed: 18576241].

10. Miller MJ, Woehr DJ, Hudspeth N. The meaning and measurement of work ethic: Construction and initial validation of a multidimensional inventory. J Vocat Behav. 2002;60(3):451-89. doi: 10.1006/jvbe.2001.1838.

11. Weber M. The Protestant ethic and the spirit of capitalism: The Talcott Parsons translation interpretations. WW Norton \& Company; 2009.

12. Seidman S. Contested knowledge: Social theory today. John Wiley \& Sons; 2016.

13. Catanzaro RD. Quantitative analysis of work ethics and need to achieve in a Peruvian university population. University of Phoenix; 2010.

14. Chudzicka-Czupała A, Cozma I, Grabowski D, Woehr DJ. A comparison of the Multidimensional Work Ethic Profile across two countries. J Manage Bus. 2012;3(1):14-33.

15. Lim DH, Woehr DJ, You YM, Allen Gorman C. The translation and development of a short form of the Korean language version of the multidimensional work ethic profile. Human Resour Dev Int. 2007;10(3):31931. doi: 10.1080/13678860701515406.

16. Murtaza G, Abbas M, Raja U, Roques O, Khalid A, Mushtaq R. Impact of islamic work ethics on organizational citizenship behaviors and knowledge-sharing behaviors. J Bus Ethics. 2014;133(2):325-33. doi: 10.1007/s10551-014-2396-0.

17. Sayadi S, Safdarian A, Ghafari H, Kaveh D. Studying the impact of islamic ethical indicators on organizational commitment of managers and employees. Spectrum. 2014;3(9):314-24.

18. Ahmad MS. Work ethics: an Islamic prospective. J Human Sci. 2011;8(1):850-9.

19. Khan AS, Rasheed F. Human resource management practices and project success, a moderating role of Islamic Work Ethics in Pakistani project-based organizations. Int J Proj Manage. 2015;33(2):435-45. doi: 10.1016/j.ijproman.2014.08.006.

20. Sehhat S, Ashena M, Parsa S. Positive psychological capital: The role of islamic work ethics in tehran public organizations. Iran J Manage Stud. 2015;8(4):545-66.

21. Tabrizi R, Akbari M, Lankarani KB, Heydari ST, Masoudi A, Shams AH, et al. Relationship between religion and school students' road behavior in southern Iran. Chin J Traumatol. 2017 doi:10.1016/j.cjtee.2016.12.001. [PubMed: 28330803]. 
22. Sadati AK, Lankarani KB, Gharibi V, Fard ME, Ebrahimzadeh N, Tahmasebi S. Religion as an empowerment context in the narrative of women with breast cancer. J Relig Health. 2015;54(3):1068-79. doi: 10.1007/s10943-014-9907-2. [PubMed: 25008190].

23. Parboteeah KP, Paik Y, Cullen JB. Religious groups and work values. Int J Cross Cult Manag. 2009;9(1):51-67. doi:10.1177/1470595808096674.

24. Evans J. Men nurses: a historical and feminist perspective. $J$ Adv Nurs. 2004;47(3):321-8. doi: 10.1111/j.1365-2648.2004.03096.x. [PubMed: 15238127].

25. Yang CI, Gau ML, Shiau SJ, Hu WH, Shih FJ. Professional career development for male nurses. JAdv Nurs. 2004;48(6):642-50. doi:10.1111/j.1365- 2648.2004.03252.x. [PubMed: 15548255].

26. Clow KA, Ricciardelli R, Bartfay WJ. Are you man enough to be a nurse? The impact of ambivalent sexism and role congruity on perceptions of men and women in nursing advertisements. Sex Roles. 2014;72(78):363-76. doi: 10.1007/s11199-014-0418-0.

27. Takase M, Maude P, Manias E. Impact of the perceived public image of nursing on nurses' work behaviour. J Adv Nurs. 2006;53(3):333-43. doi: 10.1111/j.1365-2648.2006.03729.x. [PubMed: 16441539].

28. Herring JL. Media influence on the work ethic among the baby boom generation. Iowa State University; 2007. 